\title{
Cashing Out the Check: Jorge J. E. Gracia Responds to His Critics
}

\author{
CARLOS ALBERTO SÁNCHEZ \\ San Jose State University, California, USA (carlos.sanchez@sjsu.edu)
}

ed. IVÁN JAKSIĆ, Debating Race, Ethnicity, and Nationality: Jorge J.E. Gracia and His Critics, Oxford: Oxford University Press. 224 pp.

Jorge Gracia's foundational role in the history of Latino philosophy is unquestionable. The present collection, excellently coordinated by Iván Jaksić, reaffirms Gracia's status by treating readers to some of those contributions to the field that have elicited the most fervor, the most criticism, and the most philosophy. The collection offers Gracia the opportunity to respond to his critics, and in the process, becomes more than a defense of his position, but an opportunity for clarification as well as an invitation for further thinking.

This book is divided into three parts. Each part is organized around themes or suggestions found in three of Gracia's works, Surviving Race, Ethnicity, and Nationality (Part I), Hispanic/Latino Identity: A Philosophical Perspective (Part II), and Latinos in America (Part III). These themes and suggestions are formulated as difficult philosophical questions that philosophers, or anyone interested in clarity, precision, and understanding, ought to be asking. These questions repeat themselves throughout: What is philosophy? How ought we to characterize race? Ethnicity? Nationality? What constitutes "Latino" identity? "Hispanic" identity? What's the difference between the two? And why should we care? In his various publications over the past 20 years, Gracia has offered answers to these questions, and on the basis of those critiques leveled against his position, as the one's presented in this volume, has clarified and refined his positions. In the interest of space, and because most of the critical parts have been published and discussed elsewhere, the bulk of what remains will focus on key moments in Gracia's illuminating responses.

But before getting to that, the editorial work of Jaksic should be commended. He has done readers a great service in his organization and editorial choices. His Introduction introduces the non-familiar to the field and to Gracia's legacy in a comprehensive yet rigorous way. Most relevantly, Jaksić outlines in clear and precise terms Gracia's contributions to the philosophical debate on race and ethnnicity. The key to a fruitful confrontation with the present collection is to understand the manner in which race, ethnicity and nationality are used in the debate, and especially how Gracia uses them. Gracia conceives of race "in terms of descent and genetically transmittable physical features," a view he calls the "Genetic Common-Bundle View" (7). Ethnicity is distinct from race in that ethnicity is always historically contingent while "ethne function as extended families," a view he calls the "Familial-Historical View" (ibid.). Finally, nationality has to do with "political organization on the basis of the common will exercised in accordance with the good of the people" (ibid.).

Part I is devoted to questions regarding race, ethnicity, nationality, and philosophy. The criticisms here are fascinating in their own right and obligatory reading for those interested in these topics. One of these criticisms, however, seems to discombobulate Gracia more than the rest, and it has to do with the nature of philosophy itself. Lucius Outlaw, Jr. charges Gracia with promoting a "grossly inflated job description for [...]

Journal of World Philosophies 1 (Winter 2016): 155-158

Copyright (C) 2016 Carlos Alberto Sánchez.

e-ISSN: 2474-1795 • http://scholarworks.iu.edu/iupjournals/index.php/jwp • doi: 10.2979/jourworlphil.1.1.14 
"philosophy" (33), which extends to the role that philosophy can or ought to have in discussions of race, ethnicity, nationality or any other highly problematic topic. According to Gracia, philosophy's role must be one of clarifying the concepts while serving as a final source of legitimacy. This is a metaphilosophical point and Outlaw makes the most out of it by challenging Gracia to reconsider philosophy's practical limitations. The title of Outlaw's essay says it all, "Writing a Check that Philosophy Can't Cash" (29-37). What can't be cashed out is Gracia's claim that "Philosophy tries to produce a comprehensive view that integrates all the knowledge [...] philosophy stands guard over other disciplines. And philosophy [...] sits in judgment over them" (34). Outlaw's challenge is echoed by Linda Alcoff (38-47) but in the context of pointing out philosophy's limits in the discussion of race and ethnicity, namely, that the philosopher cannot provide a context-free interpretation of these since philosophers are "of the societies which we analyze" and always stand "within the political domain of meaning and interests rather than standing apart from them" (42). To this, Gracia's answer is simply that his readers have misunderstood him or have "been misled by my rhetoric" (72). Gracia insists in his "Response" (65-87) that for him philosophy is "an unfinished business" (68) and that complete objectivity is impossible, although "it is important to aim for objectivity" (71). This is not to say that Gracia does not believe that philosophy, or something like it ("call it X, if you will" [73]), ought to aspire to integrate, guard, and judge other disciplines and other knowledges. However, Gracia maintains that a "theory should be held provisionally [...] because its very grounds are limited and contextual, and these limitations and conditions are in a constant process of change and expansion" (70). In this spirited defense we get a feel for Gracia's aspirational account of philosophy, which holds that we can aspire for philosophy to integrate, judge, guard, and achieve objectivity so long as we understand that everything can change and our aspirations can fall flat. So, ultimately Outlaw's challenge that philosophy can't be charged with doing all the things that Gracia wants it to do, is met with a bit of back-peddling: "the discipline of philosophy," he says, "is what we make of it, and it is always in the making" (74).

Part II deals with Hispanic/Latino identity and with criticisms of the issues Gracia raises in his important and seminal work, Hispanic/Latino Identity: A Philosophical Perspective. These provocative issues include the nature of ethnic identities, and whether Hispanic/Latinos constitute an ethnic group; the problematic of ethnic labels, and whether "Hispanic" or "Latino" are useful or valuable labels; the historical origins of the Hispanic/Latino ethnos; and, finally, the perception of Hispanic/Latinos in US philosophy. Critical responses to this text abound, and Jaksić has chosen an excellent representative sample of previously published or presented texts. In Gracia's response he aims to defend himself on eleven different fronts. Here I will look at two of these fronts, formulated around the questions: What is the Role of Culture and Language in Ethnicity in General and in Hispanic/Latino Identity in Particular? and What Should the Role of Hispanic/Latino Philosophy be in American Philosophy? As to the first of these, namely, the role culture and language play in ethnicity in general and Hispanic/Latino identity in particular, Gracia begins by clarifying his conception of culture as (1) "living, evolving phenomenon" that is (2) "the result of history" (169). Gracia's historicism in regards to culture also asserts that culture is a "result" of "human action" (171). This historicist, non-essentialism about culture extends to ethnicity, which is likewise culturally and historically informed. A non-essentialism that also explains Gracia's refusal to name any properties that could be claimed as necessary and sufficient conditions for Hispanic/Latino identity, such as familiarity with the Spanish language (172).

Ultimately, Gracia wants to make a normative claim about essentialist conceptions of ethnicity, identity, or culture, namely, that one ought not to essentialize these as their essentialization can only cause harm. He writes, "The idea that ethnic groups have properties that define them, including languages, tends to fuel the kind of nationalistic and ethnic feelings and policies that have caused much harm and pain to humans. "Not having an essence," he says, "is reassuring" (173). In regards to the second question, which is the ninth front Gracia takes against his critics, he says that the role of Hispanic/Latino philosophy in American philosophy

Journal of World Philosophies 1 (Winter 2016): 155-158

Copyright (C 2016 Carlos Alberto Sánchez.

e-ISSN: 2474-1795 • http://scholarworks.iu.edu/iupjournals/index.php/jwp • doi: 10.2979/jourworlphil.1.1.14 
should be to "give American philosophy a point of contrast from which to examine itself and philosophy in general; and it can provide a balancing point to what is often too one-sided and hegemonic" (175). He gives this answer after a useful summary of his views regarding Latin American philosophy, and its lack of defining properties. Despite this lack, however, Gracia suggests that if it did have one property it would be its marginality, the fact that it "has been marginalized within the European and Anglo-American context" but has nevertheless continued to develop "at the margins of the hegemonic ideological currents that dominate the world" (ibid.).

Part III concerns Latino philosophy in general, both in the US and in Latin America, while also dealing with issues that ought to be (presumably) important to Hispanic/Latino philosophers in the US, such as affirmative action, language rights, and Latin American philosophy itself. In his response, Gracia spends the majority of time addressing criticism of his proposal that "Latino philosophy" is "ethnic philosophy," a proposal intended to allow for greater inclusion into the philosophical canon of "works whose status is controversial" (228) and of his proposal that "Latino philosophy" can designate both the philosophical efforts of Latinos in the US and what we've come to know as Latin American philosophy. Susana Nuccetelli (195-202) criticizes Gracia on the basis that the sought-after inclusion does not take place, since he is ultimately reluctant to consider works such as the Popol $V u h$ as part of Latin American philosophy because the question into its status is, according to Gracia, "not philosophically interesting" (199; my emphasis). Gracia responds to Nuccetelli by making a distinction between what he does and the work of the historian of Latin American philosophy. What he does involves resolving "theoretical difficulties that arise when one considers the task of composing a history of Latin American philosophy," not "composing histories," which is the kind of work that would be required in order to evaluate the status of a work like the Popol Vub (228). His work is that of a historiographer, not a historian. Someone unfamiliar with this debate might wonder as to why Latinos are so confused about what is and what is not philosophy, ethnic or not, or about what counts and what doesn't count as philosophy. When was the last time European philosophers concerned themselves with figuring out if Sartre's "The Wall" could be "judged to satisfy certain criteria of belonging to the philosophy of an ethnos" (230). But, my guess is that this book is not intended for them. Toward the end of his response, Gracia addresses the claim that Latino philosophy as he characterizes it does not capture the empirical differences between Latino philosophers in the US and Latino philosophers in Latin America, obvious differences such as history and language, and not-so-obvious differences such as the fact that Latino philosophers in the US suffer from discrimination in the academy while Latino philosophers in Latin American generally do not (241). Gracia's response is consistent with the overall non-essentialism of his work suggesting that not all Latinos in the US suffer from discrimination while not all Latin American philosophers do not. In general, Gracia reads this particular critique as suggesting that certain properties should define what counts as Latino philosophy, which, again, he reads as a demand for necessary and sufficient conditions that he consistently rejects throughout.

This book will bring up to speed everyone interested in Gracia's contribution to the foundation, the role, and the future of Latina/o philosophy. Not only is it an excellent collection of critical responses to Gracia's philosophy, Gracia's responses to his critics are illuminating illustrations of a great thinker's ability to adapt to valid criticism, to appropriate great ideas, and to refuse those points based on misunderstandings. But they also serve as clear and mature articulations of his philosophical positions given those criticisms, which is where I think the real value of this text to be located, and which is why I have chosen to focus the review in the way that I have. On a final note, the book serves as an important reminder of what Gracia represents to those of us who work in the area of Latin American, Latino/a, and Hispanic thought and philosophy. Gracia introduced the field to many of us and his work has opened up that field to areas that I'm sure he himself did not imagine. More importantly, his diagnoses of the Latino condition in philosophy remind us of obstacles still to be overcome as we aspire for greater acceptance and greater inclusion. And so I find solace in some of his most ominous descriptions, such as when he points out: "Latino philosophers suffer discrimination primarily insofar

Journal of World Philosophies 1 (Winter 2016): 155-158

Copyright (C 2016 Carlos Alberto Sánchez.

e-ISSN: 2474-1795 • http://scholarworks.iu.edu/iupjournals/index.php/jwp • doi: 10.2979/jourworlphil.1.1.14 
as they do Latino philosophy, and particularly when they do it exclusively" (242). As someone who does it exclusively, it's comforting, as well as empowering, to know that this fact has found a home in the philosophical consciousness of our day, and that so long as it remains there, constant vigilance can only protect us.

Carlos Alberto Sánchez is Professor of Philosophy at San José State University. He writes on the philosophy of culture, the phenomenology of immigration, and the history of Mexican philosophy in the 20th century. 